\title{
Influence of temperature and gas atmosphere on in-vitro fertilization and embryo development in domestic cats
}

\author{
L. A. Johnston ${ }^{1,2, *}$, A. M. Donoghue ${ }^{1}$, S. J. O’Brien ${ }^{2}$ and D. E. Wildt ${ }^{1, \dagger}$ \\ ${ }^{1}$ National Zoological Park, Smithsonian Institution, Washington DC 20008, USA; and ${ }^{2}$ Laboratory \\ of Viral Carcinogenesis, National Cancer Institute, Frederick Cancer Research and Developmental \\ Center, Frederick MD 21702, USA
}

\begin{abstract}
Summary. The influence of culture temperature and gas atmosphere on in-vitro fertilization and embryo development was examined in the domestic cat. In Exp. 1, eggs were fertilized and cultured in $5 \% \mathrm{CO}_{2}$ in air at 37,38 or $39^{\circ} \mathrm{C}$. Experiment 2 evaluated the effects of $5 \% \mathrm{CO}_{2}$ in air; $5 \% \mathrm{CO}_{2}, 5 \% \mathrm{O}_{2}$ and $90 \% \mathrm{~N}_{2}$; and $10 \% \mathrm{CO}_{2}$ in air. Fertilization (cleavage) and development to the morula/blastocyst stage were not influenced $(P>0.05)$ by variations in temperature and gas composition. Despite changing these culture conditions, egg cleavage averaged $\sim 75 \%$ and $>80 \%$ of the 2 -cell embryos proceeded to morulae in vitro. However, the partial in-vitro morula-toblastocyst developmental block normally observed in this species was not removed.
\end{abstract}

Kelvords: cat; fertilization; embryo; in-vitro culture; incubation; temperature; gas atmosphere

\section{Introduction}

There are 3 reasons for sustaining in-vitro-fertilized felid embryos in culture until later developmental stages. First, access to more-advanced embryos allows transfer of embryos directly to the uterus by less invasive approaches than surgical oviducal transfer. Secondly, successful embryo cryopreservation may require later-stage embryos because, in some species, embryos containing 8 or fewer blastomeres have reduced post-thaw viability (see review, Wilmut, 1986). Thirdly, understanding the fundamental nutritive and energy requirements for preimplantation cat embryos provides comparative information for other carnivore taxa, most of which have never been studied. In-vitro fertilization (IVF) and embryo transfer could play an important role in managing rare felid species (Wildt, 1990). Recently, advances in IVF and culture techniques in domestic cats (Goodrowe et al., 1988; Johnston et al., 1990) have been adapted for leopard cats (Goodrowe et al., 1989), pumas (Miller et al., 1990) and tigers (Donoghue et al., 1990). Felid IVF embryos, surgically transferred to the oviducts, are viable as demonstrated by the production of live offspring in the Indian desert cat (Pope et al., 1989) and tiger (Donoghue et al., 1990). However, for IVF to be practical in such species, it will be necessary to culture embryos to morulae and blastocysts before transfer directly into the uterine lumen by an atraumatic technique such as laparoscopy (Schiewe $e t$ (al., 1984).

Although IVF and in-vitro development to morulae can be achieved routinely in domestic cats, most of the embryos exhibit a developmental block and are unable to advance to blastocysts (Johnston et al., 1991). A similar observation has been made for cultured tiger embryos produced by IVF (Donoghue et al., 1990). We recently reported that the type of culture medium and protein supplement used has a greater impact on embryo growth than on IVF in cats (Johnston et al., 1991). Although supplementing the culture medium with serum partially circumvents the morula-

*Present address: Henry Doorly Zoo, 3701 So. 10th St, Omaha, NE 68107, USA.

† Reprint requests. 
to-blastocyst block, $70-80 \%$ of these embryos remain incapable of forming blastocysts. There are several reports that incubation temperature influences oocyte maturation, fertilization and cleavage rates (Lenz et al., 1983; Eng et al., 1986; Lavy et al., 1988). Altering $\mathrm{CO}_{2}$ content in the culture environment can also affect in-vitro embryo development (see review, Wright \& Bondioli, 1981; Carney \& Bavister, 1987).

This study examined the role of temperature and gas-phase composition on IVF and embryo development in domestic cats.

\section{Materials and Methods}

Animals. Twenty-nine adult, female cats and a single male sperm donor were housed as described previously (Goodrowe et al., 1988; Johnston et al., 1991), fed a commercial feline diet (Purina Cat Chow, Ralston Purina, St Louis, MO, USA) and provided with water ad libitum. All cats were exposed to a 12-h light:12-h dark cycle.

Induction of ovarian activity and egg recovery. Females were checked daily for oestrus (Wildt et al., 1978) and those demonstrating no signs of sexual receptivity were given 150 iu pregnant mares' serum gonadotrophin (PMSG; i.m., Sigma Chemical Co., St Louis, MO, USA) to stimulate ovarian follicular development (Goodrowe et al., 1988); $84 \mathrm{~h}$ later, each female was injected with 100 iu human chorionic gonadotrophin (hCG; i.m., Sigma Chemica! Co.) and, $24-27 \mathrm{~h}$ after that, eggs were recovered laparoscopically from ovarian follicles ( $\geqslant 2 \mathrm{~mm}$ in diameter) (Goodrowe et al., 1988). Follicular content was aspirated into collection tubes containing Ham's Fl0 (Johnston et al., 1991; Irvine Scientific, Irvine, CA, USA) supplemented with 40 units of heparin $/ \mathrm{ml}$. Collection tubes were maintained at $35-37^{\circ} \mathrm{C}$ during and after aspiration. The content of each tube was emptied into a plastic culture dish and searched for mature (Goodrowe et al., 1988) eggs, which were transferred to fresh Ham's F10. On any given day, eggs from all donors (usually 3-4 cats/day) were pooled and then assigned randomly for use in Exp. 1 (temperature effects) or Exp. 2 (gas effects).

Collection and processing spermatozoa. A single, proven breeder male was used as a sperm donor to control potential male effects on fertilization and embryo development (Fukui et al., 1988). Semen was collected using a standardized electroejaculation technique (Wiidt et al., 1983) and a highly motile spermic fraction was recovered by the swim-up technique (Goodrowe et al., 1988; Howard et al., 1990). In brief, this involved transferring the electroejaculated semen into a $1 \cdot 5-\mathrm{ml}$ conical tube (Sarstedt Inc., Princeton, NJ, USA), diluting with an equal volume of Ham's F 10 medium and then centrifuging for $8 \mathrm{~min}$ at $300 \mathrm{~g}$. The supernatant was aspirated and discarded and $150 \mu \mathrm{l}$ of Ham's F10 medium was layered slowly onto the resulting pellet and the spermatozoa were allowed to swim-up for $1 \mathrm{~h}$ at room temperature. The layered aliquot was aspirated and assessed objectively for sperm concentration and subjectively for percentage motility and progression status $(0=$ no forward movement of spermatozoa to $5=$ rapid, linear, forward movement) (Wildt et al., 1983; Howard et al., 1990). Only swim-up aliquots containing sperm with $75 \%$ motility and 3.0 progression status rating were used for IVF. Spermatozoa were diluted to a final concentration of $2 \times 10^{5}$ cells $/ \mathrm{ml}$ using the appropriate temperature- and gas-equilibrated media according to specific Exp. 1 and 2 protocols.

In-vitro fertilization, embryo culture and assessment. Mature eggs were cocultured with processed spermatozoa (6-12 oocytes/insemination drop) at the appropriate temperature (Exp. 1) or gas atmosphere (Exp. 2) After 12-18 h of culture, eggs were removed from fertilization dishes and washed in a $0.2 \%$ hyaluronidase solution (Type $1-S$ from bovine testis, Sigma Chemical $\mathrm{Co}$.) to remove cumulus cells and loosely attached spermatozoa. Eggs were placed in $100-\mu l$ drops of fresh medium, overlaid with oil and cocultured under specific treatment conditions for an additional $12-18 \mathrm{~h}$ before assessing fertilization. To determine the rate of parthenogenesis, control eggs ( 2 or more representative mature eggs from each collection) were cultured under each treatment condition in medium containing no spermatozoa.

Fertilized eggs were those which cleaved to the 2-cell stage of development within $30 \mathrm{~h}$ of being placed in culture. Cleaved embryos, maintained in specific treatments, were monitored for quality and stage of development at intervals of $24 \mathrm{~h}$ for 7 days. Embryos considered viable were those which: (i) were symmetrical (or only slightly asymmetrical), (ii) contained spherical and uniformly dark blastomeres and (iii) demonstrated development over time (increased number of blastomeres). Embryos were considered to be degenerate if blastomeres were asymmetrical, pale or lysed and the embryo had arrested in growth while maintained in vitro. Embryos with $\geqslant 32$ cells were considered as morulae, whereas embryos with a developing blastocoelic cavity were classified as early blastocysts. All embryos were stained using a DNA-specific Hoechst stain (Goodrowe et al., 1988; Johnston et al., 1989) and nuclei were counted.

Experiment 1. Ham's F10 medium, supplemented with foetal calf serum (FCS, 5\%, Irvine Scientific) was equilibrated under $5 \% \mathrm{CO}_{2}$ in air at 37,38 or $39^{\circ} \mathrm{C}$. This was accomplished by simultaneously using 3 incubators maintained at one of these temperatures, which were chosen because $37^{\circ} \mathrm{C}$ is commonly used for mammalian embryo culture, whereas 38 and $39^{\circ} \mathrm{C}$ simulate the normal core body temperature variation for domestic cats. A single electroejaculate, processed with Ham's F10, was divided, diluted and maintained at each temperature. Each experiment was repeated 3 times and the medium was prepared fresh on 3 occasions over 2 months. Eggs were 
divided randomly among the test temperatures $\left(37^{\circ} \mathrm{C}, n=57 ; 38^{\circ} \mathrm{C}, n=50 ; 39^{\circ} \mathrm{C}, n=51\right)$ and then cultured with spermatozoa previously maintained at each specific temperature.

Experiment 2. Three gas phases were evaluated: $5 \% \mathrm{CO}_{2}$ in air; $5 \% \mathrm{O}_{2}, 5 \% \mathrm{CO}_{2}$ and $90 \% \mathrm{~N}_{2}$; and $10 \% \mathrm{CO}_{2}$ in air. Based on the findings from Exp. 1, 38 ${ }^{\circ} \mathrm{C}$ was chosen as the optimal culture temperature for Exp. 2. Ham's F10 was equilibrated for a minimum of $2 \mathrm{~h}$ before use in each of the gas phases. Spermatozoa, prepared as described above, were divided into aliquots and diluted in medium equilibrated with each gas phase. The number of experimental replicates and times that medium were prepared were similar to Exp. I. The number of eggs distributed randomly among the treatments were: $5 \% \mathrm{CO}_{2}, n=68 ; 5 \% \mathrm{CO}_{2}, 5 \% \mathrm{O}_{2}$ and $90 \% \mathrm{~N}_{2}, n=62$; and $10 \% \mathrm{CO}_{2}, n=67$.

Statistical analysis. The proportion of eggs fertilized after culture with spermatozoa and the proportion of embryos developing to a specific stage are expressed as percentages. Differences in fertilization were evaluated by $\chi^{2}$ analysis.

\section{Results}

None of the control eggs, cultured in the absence of spermatozoa, in Exp. 1 or 2 cleaved.

\section{Experiment 1}

There was no effect $(P>0.05)$ of the temperatures tested on IVF success or the proportion of 2-cell embryos developing to the morula or blastocyst stages (Table 1). All temperatures allowed at least $72 \%$ of all eggs to form 2-cell embryos after $24 \mathrm{~h}$ in vitro and $>85 \%$ of these developed into morulae by $96 \mathrm{~h}$ of culture. Regardless of temperature, $<30 \%$ of all cleaved embryos reached the blastocyst stage by $120 \mathrm{~h}$ in culture.

Table 1. Effect of incubation temperature and gas phase on in-vitro fertilization and embryo development in domestic cats

\begin{tabular}{lcccc}
\hline Treatment & $\begin{array}{c}\text { No. of } \\
\text { oocytes }\end{array}$ & $\begin{array}{c}\text { No. of } \\
\text { 2-cell embryos } \\
(\%)^{*}\end{array}$ & $\begin{array}{c}\text { No. of 2-cell embryos } \\
\text { developing to morulae } \\
(\%) \dagger\end{array}$ & $\begin{array}{c}\text { No. of 2-cell embryos } \\
\text { developing to blastocysts } \\
(\%) \dagger\end{array}$ \\
\hline $\begin{array}{l}\text { Temperature }(\mathrm{C}) \\
37\end{array}$ & 57 & $46(80 \cdot 7)$ & $40(86 \cdot 9)$ & $10(21 \cdot 7)$ \\
38 & 50 & $38(76 \cdot 0)$ & $37(97 \cdot 4)$ & $11(28 \cdot 9)$ \\
39 & 51 & $37(72 \cdot 5)$ & $32(86 \cdot 5)$ & $5(13 \cdot 5)$ \\
$\begin{array}{l}\text { Gas phase } \\
5 \% \mathrm{CO}_{2} \text { in air }\end{array}$ & 68 & $52(76 \cdot 5)$ & $45(86 \cdot 5)$ & $12(23 \cdot 1)$ \\
$5 \% \mathrm{CO}_{2}, 5 \% \mathrm{O}_{2}$. & 62 & $49(79 \cdot 0)$ & $40(81 \cdot 6)$ & $17(34 \cdot 6)$ \\
$90 \% \mathrm{~N}_{2}$ & 67 & $49(73 \cdot 1)$ & $41(83 \cdot 7)$ & $11(22 \cdot 4)$ \\
$10 \% \mathrm{CO}_{2}$ in air & 6 & &
\end{tabular}

*By $24 \mathrm{~h}$ in culture.

†By $96 \mathrm{~h}$ in culture.

$\ddagger$ By $120 \mathrm{~h}$ in culture.

\section{Experiment 2}

The number of eggs fertilized in vitro and the proportion of embryos developing into morulae or blastocysts were not influenced by the variations in gas phase (Table 1). At least $73 \%$ of all eggs cleaved within $24 \mathrm{~h}$ of insemination and $>80 \%$ of these developed into morulae by $96 \mathrm{~h}$ in culture (Table 1). As in Exp. 1, $\leqslant 35 \%$ of the cleaved embryos developed into blastocysts by $120 \mathrm{~h}$ in culture. 


\section{Discussion}

The efficiency of the IVF system developed for domestic cats was unaffected by the changes in culture temperature or gaseous components. These findings, together with our recent report evaluating the effects of medium and protein supplement (Johnston et al., 1990), show that successful IVF and early embryo cleavage in domestic cats is remarkably resilient to substantial alterations in in-vitro culture conditions. The precise biological charcteristics of spermatozoa-oocyte interaction in cats are unknown, but the ability of cat spermatozoa to capacitate, bind and penetrate follicular oocytes routinely in vitro will permit further examination of this phenomenon (see review, Wildt, in press). Within the limits already tested, it is now apparent that most conventional types of medium, protein supplement, temperature and gaseous environment will support high rates of oocyte cleavage after IVF.

Imposing various experimental variables on the system appears to influence the development of 2-cell cat embryos to later preimplantation stages more than fertilization itself. Although IVF cat embryos develop efficiently to the morula stage in vitro, the present study confirmed our earlier observation (Johnston et al., 1991) of a partial morula-to-blastocyst developmental block in this species. This arrest in embryonic development may be related to chromosome anomalies, perhaps associated with exogenous gonadotrophin treatment (Sengoku \& Dukelow, 1988). We chose to assess possible environmental causes. For example, we demonstrated recently that more cat embryos cultured in Ham's F10 reach the morula stage in vitro than in a modified Tyrode (TALP) solution (Johnston et al., 1991). More embryos cultured in Ham's F10 advance to blastocysts when foetal calf serum or oestrous cat serum was the protein supplement rather than bovine serum albumin or a nonprotein control (polyvinylalcohol).

Statistical analyses revealed no marked effects of temperature or gas phase on embryo development or on the proportion of embryos advancing from morulae to blastocysts. In this context, fertilization and embryo development appear somewhat different in cats from other species. For example, greater IVF rates have been achieved in cow eggs cultured at 39 rather than $37^{\circ} \mathrm{C}$ (Lenz et al., 1983), but, at a high temperature $\left(41^{\circ} \mathrm{C}\right.$ ), mouse embryo development in vitro is compromised (Lavy et al., 1988). Our results indicated that we have not yet defined the critical maximum adverse temperature for cat embryo viability in vitro.

For several mammalian species, successful embryo development in vitro is at least partially dependent on the gaseous environment. The $\mathrm{CO}_{2}$ component is important for regulating intracellular $\mathrm{pH}$ and serving as a carbon source for development (Wales et al., 1969; Graves \& Biggers, 1970). Recently, Carney \& Bavister (1987) demonstrated that increasing $\mathrm{CO}_{2}$ from 5 to $10 \%$ improves in-vitro development of 8-cell hamster embryos to blastocysts. The stimulation by increased $\mathrm{CO}_{2}$ is attributed, in part, to its ability to act as a weak acid, thereby maintaining intracellular $\mathrm{pH}$. However, doubling the $\mathrm{CO}_{2}$ content had no effect on the ability of cat embryos to become morulae, and, unlike in the hamster, $\mathrm{CO}_{2}$ did not play a role in blastocyst formation. Lowering $\mathrm{O}_{2}$ also did not influence embryo growth. Similar studies in other species have produced equivocal results. For example, the development of 1- and 2-cell mouse embryos (Whitten, 1971; Quinn \& Harlow, 1978) or 2-8-cell cattle embryos (Wright et al., 1976) in vitro is enhanced by lowering the $\mathrm{O}_{2}$ atmosphere to $5 \%$, but varying the oxygen tension in the culture of 1-cell sheep embryos is highly dependent on the incubation vessel (Tervit \& Rowson, 1974; Wright et al., 1976; Betterbed \& Wright, 1985).

Overall, these results demonstrate that fertilization of domestic cat oocytes in vitro and subsequent growth to morulae are independent of incubation temperature or gas atmosphere. Many of the traditional culture variables (medium, protein source, incubation temperature and gas phase) can be changed (within conventional limits) without severely compromising fertilization or culture success rates. Despite alterations in culture environment, egg cleavage rate is usually $\sim 75 \% ;>80 \%$ of these 2 -cell embryos proceed to morulae in vitro, but, even under optimum 
conditions, $>65 \%$ of all IVF embryos remain arrested as morulae in culture. We conclude that the partial developmental block to blastocyst formation in cats is a highly complex phenomenon regulated by factors other than type of medium, temperature or gaseous constituents in the culture environment.

We thank S. L. Hurlbut for technical assistance and K. James and R. Frye of the National Institutes of Health Animal Center for animal care. This project was funded, in part, by grants to Dr Wildt from the National Institutes of Health (NIH HD 23583) and the Friends of the National Zoo (FONZ).

\section{References}

Betterbed, B. \& Wright, R.W., Jr. (1985) Development of one-cell ovine embryos in two culture media under two gas atmospheres. Theriogenology 23, 547-553.

Carney, E.W. \& Bavister, B.D. (1987) Regulation of hamster embryo development in-vitro by carbon dioxide. Biol. Reprod. 36, 1155-1163.

Donoghue, A.M., Johnston, L.A., Seal, U.S., Armstrong, D.L., Tilson, R.L., Wolf, P., Petrini, K., Simmons, L.G., Gross, T. \& Wildt, D.E. (1990) In-vitro fertilization and embryo development in vitro and in vivo in the tiger (Panthera tigris). Biol. Reprod. 43, 733-747.

Eng, L.A., Kornegay, E.T., Huntington, J. \& Wellman, T. (1986) Effects of incubation temperature and bicarbonate on maturation of pig oocytes in vitro. $J$. Reprod. Fert. 76, 657662.

Fukui, Y., Glew, A.M., Gandolfi, F. \& Moor, R. M. (1988) Ram-specific effects on in-vitro fertilization and cleavage of sheep oocytes matured in vitro. $J$. Reprod. Fert. 82, 337-340.

Goodrowe, K.L., Wall, R.J., O'Brien, S.J., Schmidt, P.M. \& Wildt, D.E. (1988) Developmental competence of domestic cat follicular oocytes after fertilization in vitro. Biol. Reprod. 39, 355--372.

Goodrowe, K.L., Miller, A.M. \& Wildt, D.E. (1989) In-vitro fertilization of gonadotropin-stimulated leopard cat (Felis bengalensis) follicular oocytes. $J$. exp. Zool. 252, 89-95.

Graves, C.N. \& Biggers, J.D. (1970) Carbon dioxide fixation by mouse embryos prior to implantation. Science, N.Y. 167, 1506-1508.

Howard, J.G., Brown, J.L., Bush, M. \& Wildt, D.E. (1990) Teratospermic and normospermic domestic cats: ejaculate traits. pituitary-gonadal hormones and improvement of sperm viability and morphology after swim-up processing. J. Androl. 11, 204-215.

Johnston, L.A., O'Brien, S.J. \& Wildt, D.E. (1989) In-vitro maturation and fertilization of domestic cat follicular oocytes. Gamete Res. 24, 343-356.

Johnston, L.A., Donoghue, A.M., O'Brien, S.J. \& Wildt, D.E. (1991) Culture medium and protein supplementation influence in-vitro fertilization and embryo development in the domestic cat. J. exp. Zool. 257 , 350359.

Lavy, G., Diamond, M.P., Pellicer, A., Vaughn, W.K. \& Decherney, A.H. (1988) The effect of the incubation temperature on the cleavage rate of mouse embryos in-vitro. J. In Vitro Fert. Embryo Transfer 5, 167-170.

Lenz, R.W., Ball, G.D., Leibfried, M.L., Ax, R.L. \& First, N.L. (1983) In-vitro maturation and fertilization of bovine oocytes are temperature-dependent processes. Biol. Reprod. 29, 173-179.
Miller, A.M., Roelke, M.E., Goodrowe, K.L., Howard, J.G. \& Wildt, D.E. (1990) Oocyte recovery, maturation and fertilization in-vitro in the puma (Felis concolor). J. Reprod. Fert. 88, 249-258.

Pope, C.E., Gelwicks, E.J., Wachs, K.B., Keller, G.L., Maruska, E.J. \& Dresser, B.L. (1989) Successful interspecies transfer of embryos from the Indian desert cat (Felis silvestris ornata) to the domestic cat (Felis catus) following in-vitro fertilization. Biol. Reprod. 40 (Suppl. 1), 61, abstr.

Quinn, P. \& Harlow, G.M. (1978) The effect of oxygen on the development of preimplantation mouse embryos in vitro. J. exp. Zool. 206, 73-80.

Schiewe, M.C., Bush, M., Stuart, L.D. \& Wildt, D.E. (1984) Laparoscopic embryo transfer in domestic sheep: a preliminary study. Theriogenology 22, $675-682$.

Sengoku, K. \& Dukelow, W.R. (1988) Gonadotropin effects on chromosomal normality of hamster preimplantation embryos. Biol. Reprod. 38, 150-155.

Tervit, H.R. \& Rowson, L.E.A. (1974) Birth of lambs after culture of sheep ova in vitro for up to 6 days. $J$. Reprod. Fert. 38, 177-179.

Wales, R.G., Quinn, P. \& Murdoch, R.N. (1969) The fixation of carbon dioxide by the 8-cell mouse embryo. J. Reprod. Fert. 20, 541-543.

Whitten, W.K. (1971) Nutrient requirements for the culture of preimplantation embryos in-vitro. Advances in the Biosciences, Vol. 6. Pergamon Press, New York.

Wildt, D.E. (1990) Potential applications of IVF technology for species conservation. In Fertilization in Mammals, pp. 349-364. Eds B. D. Bavister, J. Cummins \& E. R. S. Roldan. Serono Symposium USA, Norwell.

Wildt, D.E. (in press) Fertilization in cats. In $A$ Comparative Overview of Mammalian Fertilization. Eds B. S. Dunbar \& M. O'Rand. Plenum Press, New York.

Wildt, D.E., Charman-Guthrie, S. \& Seager, S.W.J. (1978) Ovarian and behavioral cyclicity of the laboratory maintained cat. Horm. Behav. 10, 251-257.

Wildt, D.E., Bush, M., Howard, J.G., O'Brien, S.J., Meltzer, D., van Dyk, A., Ebedes, H. \& Brand, D.J. (1983) Unique seminal quality in the South African cheetah and a comparative evaluation in the domestic cat. Biol. Reprod. 29, 1019-1025.

Wilmut, I. (1986) Cryopreservation of mammalian eggs and embryos. In Developmental Biology. Volume 4. Manipulation of Mammalian Development, pp. 217247. Ed R. B. L. Gwatkin. Plenum Press, New York. 
Wright, R.W., Jr., Anderson, G.B., Cupps, P.T. \& Drost, Wright, R.W., Jr. \& Bondioli, K.R. (1981) Aspects of M. (1976) Successful culture in-vitro of bovine embryos to the blastocyst stage. Biol. Reprod. 14, $157-162$. in-vitro fertilization and embryo culture in domestic animals. J. Anim. Sci. 53, 702-729.

Received 14 August 1990 